SSC03-IX-1

\title{
SIMONE: Interplanetary Microsatellites for NEO Rendezvous Missions
}

\author{
Dr. Roger Walker \\ Space Department, QinetiQ, Farnborough, Hampshire, GU14 0LX, United Kingdom \\ Tel.: +44 1252 392721, E-mail: rjwalker@space.qinetiq.com \\ Mr. Nigel Wells \\ Space Department, QinetiQ, Farnborough, Hampshire, GU14 0LX, United Kingdom \\ Tel.: +44 1252 395791, E-mail: nswells@space.qinetiq.com \\ Dr. Simon Green \\ Planetary \& Space Sciences Research Institute, Open University, Milton Keynes, MK7 6AA, United Kingdom \\ Tel.: +44 1908 659601, E-mail: s.f.green@open.ac.uk \\ Dr. Andrew Ball \\ Planetary \& Space Sciences Research Institute, Open University, Milton Keynes, MK7 6AA, United Kingdom \\ Tel.: +44 1908 659596, E-mail: a.j.ball@open.ac.uk
}

\begin{abstract}
The paper summarises a novel mission concept called SIMONE (Smallsat Intercept Missions to Objects Near Earth), whereby a fleet of microsatellites may be deployed to individually rendezvous with a number of Near Earth Objects (NEOs), at very low cost. The mission enables, for the first time, the diverse properties of a range of spectral and physical type NEOs to be determined. Such data are invaluable in the NEO scientific, impact damage prediction, and impact countermeasure planning contexts. The five identical $120 \mathrm{~kg}$ spacecraft are designed for low-cost piggyback launch on the Ariane-5 into GTO, from where each uses a high specific impulse gridded-ion engine to escape Earth gravity and ultimately to rendezvous with a different NEO target. The primary challenge with such a mission is the ability to accommodate the necessary electric propulsion, power, payload and other onboard systems within the severe constraints of a microsatellite. The paper describes the way in which the latest technological advancements and innovations have been selected and applied to the mission design. The SIMONE design is feasible and offers a highly cost-effective mission, which is applicable to other solar system science/exploration objectives. SIMONE clearly demonstrates that the concept of an "interplanetary microsatellite" is now realisable.
\end{abstract}

\section{Introduction}

Exploration of the solar system, including small bodies such as asteroids, is a very demanding application of space technology. It has traditionally required a dedicated high energy launch and also a spacecraft with a significant propulsive capability. Such missions can therefore be both large and costly, although medium-sized missions have also flown at a moderate cost recently ${ }^{1}$. However, truly low-cost access to the frontier is now within reach with the advent of the "interplanetary microsatellite".

Recent developments in key enabling technologies have been brought together to form a highperformance microsatellite bus design that has a significant delta-V capability of $10 \mathrm{~km} / \mathrm{s}$, whilst carrying a number of miniaturised but capable payload instruments. The key enabling technology is low-thrust, very high-specific impulse ion propulsion. Recently validated by the Deep Space 1 mission $^{2}$, ion propulsion combines a high delta- $\mathrm{V}$ capability with very low fuel consumption. By integrating this emerging technology into a microsatellite system of $<120 \mathrm{~kg}$ mass, solar system exploration such as asteroid rendezvous, can be done for a fraction of the cost of a traditionally larger, chemically propelled mission. The microsatellite must generate high power to drive the ion engine. This power can be made available to the payload and on-board communications system for the data downlink to a commercial deep space network provider, when the ion engine is not operating.

The small-sized bus substantially reduces mission cost by enabling cheap access to space via piggyback or ride-sharing launch opportunities into high Earth orbit, and a rapid development and build schedule. Significant design challenges arise when attempting to integrate the ion propulsion system into the confines of a small bus, and supporting its high power requirements (500-1000W). However, these difficulties have been overcome during detailed studies of the concept and feasibility of the SIMONE mission for the European Space Agency $^{3}$, as described below in this paper. 


\section{$\underline{\text { The Mission }}$}

\section{Mission Concept}

SIMONE is a unique interplanetary mission concept comprising a fleet of low-cost microsatellites that will individually rendezvous with a different Near Earth Object (NEO), each of a distinct spectral and/or physical type. In-situ science measurements taken by instruments on-board each spacecraft enable the wide diversity in the physical and compositional properties of the NEO population to be characterised in a highly cost-effective manner. Analysis of the in-situ measurement data will provide:

- valuable scientific knowledge on the nature, origin and processing of NEOs;

- critical physical/compositional information needed for the accurate prediction of impact risk (particularly damage potential) posed by NEOs;

- critical physical/compositional information needed for the development of effective NEO risk mitigation strategies that are specifically tailored for each NEO type.

The SIMONE mission team is led by QinetiQ formerly DERA - (UK) in partnership with the Planetary and Space Sciences Research Institute (PSSRI) of the Open University (UK), with additional expertise provided by SciSys (UK), Politecnico di Milano (Italy) and Telespazio (Italy).

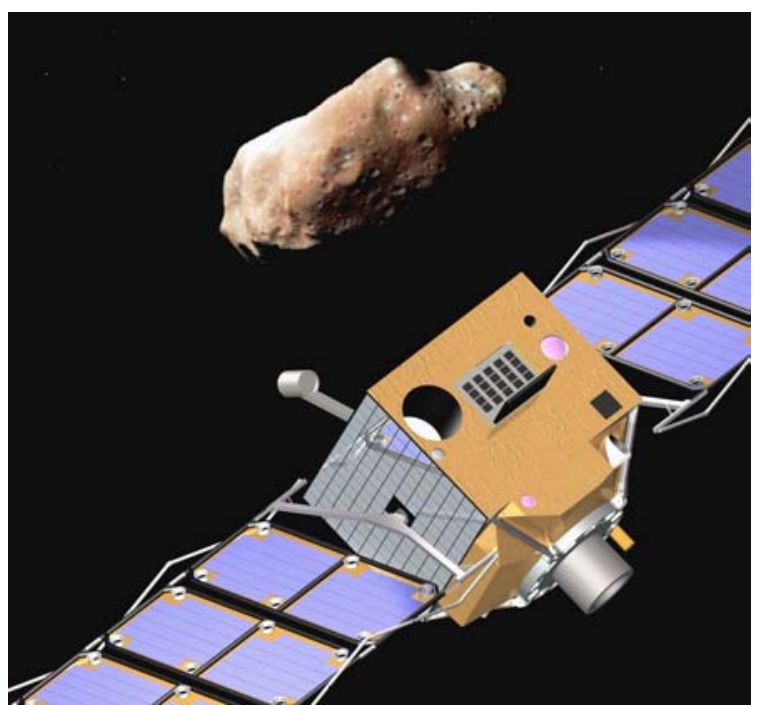

Figure 1. The SIMONE microsatellite during rendezvous with a NEO target (image of Ida courtesy of NASA)

\section{Mission Overview}

SIMONE can be realised by the use of microsatellite technology - this would be a world-first for an interplanetary mission. Conducting multiple NEO rendezvous missions with large conventional spacecraft would be prohibitively expensive. It is planned to deploy 5 of the SIMONE microsatellites to their intended rendezvous targets within the budget envelope of $\$ 150 \mathrm{M}$. In order to achieve this target, a low-cost approach to the programme as a whole is needed.

The SIMONE microsatellites (see Figure 1) are based around a single spacecraft system design, configuration and payload, and a single ground segment, thereby significantly lowering recurring costs. "Piggyback" launch opportunities on the Ariane Structure for Auxiliary Payloads (ASAP) on Ariane-5 will be exploited in order to obtain low launch costs (see Figure 2). Traditionally, launch costs are a significant cost driver for interplanetary missions because a dedicated deep space launch is usually required for direct injection onto an interplanetary trajectory. Instead, these launches will place each SIMONE spacecraft into a Geostationary Transfer Orbit (GTO). From GTO, on-board propulsion is used to achieve an Earth escape trajectory, adjust the interplanetary trajectory, eventually rendezvous with the target NEO and conduct close reconnaissance around the target.

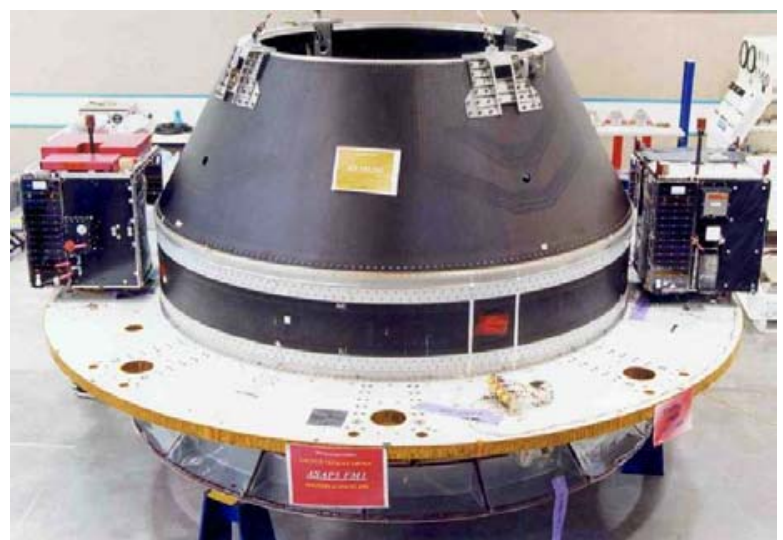

Figure 2. QinetiQ STRV microsatellites mounted on the Ariane-5 ASAP destined for GTO

\section{Mission Constraints}

The main design constraints placed on such a lowcost mission arise from the build, launch and operations elements of the project. The development schedule, from detailed design to launch, is foreseen to be no more than 4 years for all 5 spacecraft. For launch as a piggyback payload on an Ariane 5, the mass of each spacecraft is limited to $120 \mathrm{~kg}$. The available volume for a single spacecraft bus on the launcher is a box of no more than $600 \times 600 \times 710 \mathrm{~mm}$, with a negotiated waiver for the stowed solar array wings of $200 \times 300 \times 700 \mathrm{~mm}$ either side of the bus. As an auxilliary passenger, there is also no influence over the launch date/window, requiring a flexible mission design strategy. The total 5-flight mission duration is limited to 5 years in order to reduce ground segment costs and space segment component costs. 
Table 1: Summary of the SIMONE mission phases

\begin{tabular}{|c|c|c|c|}
\hline \multirow[b]{3}{*}{1} & & \multirow[b]{2}{*}{ Duration } & \multirow[b]{2}{*}{ Description } \\
\hline & Mission Phase & & \\
\hline & $\begin{array}{l}\text { Launch and Early } \\
\text { Orbit Phase (LEOP) }\end{array}$ & $\sim 3-4$ days & $\begin{array}{l}\text { Deployment from an Ariane- } 5 \text { launch vehicle into GTO, and } \\
\text { attainment of a stable } 3 \text {-axis attitude control mode following ejection } \\
\text { from the Ariane upper stage }\end{array}$ \\
\hline 2 & Check Out Phase & $\sim 2$ weeks & $\begin{array}{l}\text { Complete system functional tests during visibility periods with the } \\
\text { ground station. }\end{array}$ \\
\hline \multirow[t]{2}{*}{3} & Parking Orbit Phase & $\begin{array}{l}\text { 9-12 months } \\
\text { (depending upon } \\
\text { time to optimum }\end{array}$ & $\begin{array}{l}\text { From highly eccentric GTO, raising of the orbit above the proton \& } \\
\text { electron radiation belts into a safe (i.e. low radiation dose) near- } \\
\text { circular "parking orbit" at } 300,000 \mathrm{~km} \text {. }\end{array}$ \\
\hline & & $\begin{array}{l}\text { Escape Phase } \\
\text { start) }\end{array}$ & Wait for the Earth-Escape Phase to start. \\
\hline \multirow[t]{2}{*}{4} & Earth Escape Phase & $\sim 1$ month & $\begin{array}{l}\text { Expand and phase the orbit using the on-board ion propulsion system } \\
\text { for a lunar swing-by gravity assist manoeuvre to lower delta-V and } \\
\text { propellant consumption. }\end{array}$ \\
\hline & & & $\begin{array}{l}\text { Exceed Earth gravitational sphere of influence into a heliocentric } \\
\text { orbit with an inclination similar to the target plane. }\end{array}$ \\
\hline \multirow[t]{4}{*}{5} & Rendezvous Phase & $\begin{array}{l}\text { 22-33 months } \\
\text { (depending upon }\end{array}$ & $\begin{array}{l}\text { Combination of phased long-duration low thrust arcs and coast (no } \\
\text { thrust) arcs in heliocentric orbit. }\end{array}$ \\
\hline & & $\begin{array}{l}\text { the NEO target } \\
\text { orbit) }\end{array}$ & $\begin{array}{l}\text { Follow an optimised transfer trajectory that ultimately arrives in } \\
\text { vicinity of the target at a low approach velocity and matches the } \\
\text { spacecraft's orbit with that of the target NEO orbit. Trajectory } \\
\text { correction manoeuvres are determined based upon radio navigation } \\
\text { techniques. }\end{array}$ \\
\hline & & & $\begin{array}{l}\text { Acquisition of the target } \mathrm{NEO} \text { using the imager payload for optical } \\
\text { navigation relative to the target. }\end{array}$ \\
\hline & & & $\begin{array}{l}\text { Long-range approach to the target until reaching a stand-off distance } \\
\text { from } 2000 \mathrm{~km} \text { down to } \sim 200 \mathrm{~km} \text { ready for the Measurement Phase. }\end{array}$ \\
\hline \multirow[t]{3}{*}{6} & Measurement Phase & $\sim 4$ months & $\begin{array}{l}\text { Intermediate proximity: } \\
\text { Co-fly with the target NEO at } \sim 100-200 \mathrm{~km} \text { range and take in- } \\
\text { situ measurements with the payload instruments to determine } \\
\text { size and shape. }\end{array}$ \\
\hline & & & $\begin{array}{l}\text { Close proximity: } \\
\text { - Close ballistic swing-bys of the spacecraft at a minimum } \\
\text { distance of a few NEO radii }(<10 \mathrm{~km}) \text { to determine gravity field } \\
\text { and mass. Determine bulk density from shape, mass. }\end{array}$ \\
\hline & & & $\begin{array}{l}\text { - "Imaging" swing-bys at }<10 \mathrm{~km} \text { altitude to obtain high- } \\
\text { resolution data on NEO surface features/composition. }\end{array}$ \\
\hline
\end{tabular}

\section{Mission Design}

The six different phases of each SIMONE flight are described in Table 1. Trajectory analyses were performed for each of the selected rendezvous targets by Politecnico di Milano ${ }^{4}$. Low-thrust trajectory optimisation software was used to determine minimum fuel mass trajectories for SIMONE arrival at the targets within the 5-year total mission duration constraint and with a low arrival velocity. These optimal trajectories require lunar swing-by and Earth escape to occur on specific dates to enable minimum fuel expenditure. However, there is no control over the launch date as the auxilliary launch passenger. Therefore, a flexible mission design strategy was devised to overcome this problem. This involves booking a launch that deploys well in advance of the required swingby/escape dates and raising the orbit from a GTO to a high altitude parking orbit. This is done as quickly as possible to clear the radiation belts and hence minimise solar array power degradation. The parking orbit is located at $300,000 \mathrm{~km}$ semi-major axis with eccentricity 0.25 , and is obtained by firing the engine continuously with the thrust vector aligned with the velocity vector all around the orbit arc from GTO start until parking orbit stop condition. The exception is during short eclipses when the engine power requirements cannot be met by the power system. Once in the parking orbit, the spacecraft can wait until the time for optimal lunar swingby and Earth escape to begin. Being in an orbit fairly close to the Moon, it is then easy to fire the engine to phase the orbit for targeting the lunar swingby at the correct point of the hyperbolic periapsis. This gravity assist has been determined to achieve escape with a heliocentric plane change, thus reducing the demand on the engine to match the inclination of the NEO target during the interplanetary phase. 


\section{The Science}

\section{Rationale}

The NEO population contains a wide diversity of bodies with different physical properties relating to their origin and subsequent processing by solar radiation, cosmic ray and impact effects. Groundbased optical telescope observations have enabled a number of different types of NEO to be characterised by their unique spectral signatures. From the observations, physical properties such as size, shape, rotation, surface mineralogical type can be inferred. Radar observations can give excellent information on orbit, rotation state, surface topography, and binary nature, with the latter being useful to accurately derive object mass.

Whilst remote observations permit classification of general compositional types and determination of some physical properties, the range of uncertainty of this inferred physical information is often large and insufficient for impact risk assessment and mitigation purposes. Furthermore, some information simply cannot be collected from ground observations. Only dedicated rendezvous missions can provide the indepth study of NEOs that is required to fully characterise their physical and compositional properties with high accuracy. A multiple rendezvous strategy to sample the different types of NEO at close range addresses critical gaps in our knowledge of the NEO population that would otherwise remain, even in the light of the various forthcoming missions. Filling these knowledge gaps is fundamental to how well we can define and counter the threat posed by NEOs to the Earth in the future.

The diversity of NEO physical properties (particularly bulk density) leads to great uncertainty in the magnitude of destruction that an object of a particular size would cause on Earth. The data provided by multiple rendezvous missions would allow better predictive tools to be established that would link key properties such as bulk density with parameters that can be derived from Earth-based or space-based remote observations. Such links are important in that they would allow a better initial characterisation of a potentially threatening object (in terms of size, mass and composition), thus influencing the decision regarding an effective mitigation approach.

Mitigation techniques may involve a slight deflection of a minor body by either a carefully planned impact (or series of impacts), long-term ablation of the surface, an explosive impulse, or long-term action of a low-thrust propulsive device. Understanding key properties of the surface and bulk materials of different types of NEOs and their response to heating or mechanical stress is thus crucial to the selection and development of effective mitigation techniques.
Some techniques may be wholly ineffective for certain types of target object, such as highly porous or fractured bodies. Close-up reconnaissance of diverse NEOs is a logical precursor to the success of missions dedicated to executing specific mitigation strategies.

The multiple rendezvous philosophy echoes one of the recommendations of the report of the UK Government's Taskforce on Potentially Hazardous Near Earth Objects ${ }^{5}$, namely that the case for mounting a number of co-ordinated rendezvous missions to visit different types of NEO should be explored. The recommendation goes on to suggest that they be based on relatively inexpensive microsatellites. This was the starting point for the SIMONE concept.

\section{Rendezvous Targets}

An extensive target selection process has been conducted in order to identify the most suitable Near Earth Objects (NEOs) for rendezvous by five SIMONE deep space missions, according to priorities for NEO risk assessment, science and mission feasibility. Filtering techniques were applied to the known NEO population of nearly 1,927 objects as of $2^{\text {nd }}$ July 2002. These filters were designed to reduce the population down to a shortlist of potential candidates, where the feasibility of a SIMONE rendezvous mission could be ensured in terms of accessibility, navigation to the targets, and achieving science objectives at the objects. The primary filter criteria applied to the population were:

- Delta-V to rendezvous with the NEO targets, after the Earth escape phase, must be within the remaining delta-V capability of the SIMONE spacecraft $(\sim 6 \mathrm{~km} / \mathrm{s}$ is expected, assuming a Hohmann transfer calculation);

- Size of the NEO targets must be larger than a given threshold (or brighter than a given absolute magnitude). A cut-off absolute magnitude of 19.5 is chosen, corresponding to objects larger than $300 \mathrm{~m}$ in diameter (large enough for long-range acquisition by on-board optical sensors and to represent significant Earth impact damage potential, yet small enough to maintain a diverse sample of object types).

After filtering, a shortlist containing 15 objects was generated with a good cross-section of spectral and physical types retained. The shortlist was analysed in detail and 7 targets were selected by the mission study team in order to satisfy the primary mission objective of characterising the physical/chemical properties of different types of NEO in order priority interest. These 7 target objects are summarised in Table 2, and are similar to those proposed by other authors ${ }^{6,7}$. The bottom two asteroids (in grey) are considered as secondary reserve targets. 
Table 2. Selected near-Earth asteroid targets for rendezvous by the SIMONE microsatellites

\begin{tabular}{|c|c|c|c|c|l|}
\hline Priority & Target & $\begin{array}{c}\text { Spectral } \\
\text { type }\end{array}$ & $\begin{array}{c}\text { Orbit } \\
\text { class }\end{array}$ & $\begin{array}{c}\text { Est. Diameter } \\
{[\mathbf{k m}]}\end{array}$ & Comment \\
\hline $\begin{array}{c}\text { 2 C types } \\
\text { (common, poorly characterised, low } \\
\text { density?, primitive) }\end{array}$ & $1996 \mathrm{FG} 3$ & $\mathrm{C}$ & Apollo & 1.3 effective & $\begin{array}{l}\text { 4-hour rotation } \\
\text { Binary (16-hour orbit) } \\
\text { Size ratio 0.31 }\end{array}$ \\
\cline { 2 - 6 } & $1989 \mathrm{UQ}$ & $\mathrm{CB}$ & Aten & $0.56-0.76$ & 7.7-hour rotation \\
\hline $\begin{array}{c}\text { S-type } \\
\text { (common, from inner main belt, } \\
\text { higher temperature silicates) }\end{array}$ & $1999 \mathrm{YB}$ & $\mathrm{S}$ & Apollo & 0.64 & Only S-type left \\
\hline $\begin{array}{c}\text { M-type } \\
\text { (metallic?, high density, X-types are } \\
\text { P, M or E types) }\end{array}$ & $\begin{array}{c}\text { (460) Nereus } \\
\text { 1982 DB }\end{array}$ & $\mathrm{X}$ & Apollo & $0.47-1.33$ & $\begin{array}{l}\text { 15-hour rotation } \\
\text { C-type in some refs. }\end{array}$ \\
\hline $\begin{array}{c}\text { "Pot luck" } \\
\text { (unknown type, select largest) }\end{array}$ & $1994 \mathrm{CN} 2$ & $\mathrm{X}$ & Apollo & $0.39-1.1$ & Could be P, M, or E \\
\hline $\begin{array}{c}\text { Reserve } \\
\text { (known parent body, Vesta) }\end{array}$ & $\begin{array}{c}\text { (3361) Orpheus } \\
1992 \mathrm{HR}\end{array}$ & $\mathrm{V}$ & Apollo & 0.4 & $\begin{array}{l}\text { Pawn mission target } \\
\text { 4-hour rotation }\end{array}$ \\
\hline
\end{tabular}

The two selected X-type objects may be determined as either P, M or E types after further spectral followup observations are made. Thus, a good cross-section of different NEO spectral types can be characterised by the SIMONE rendezvous missions for risk assessment (C-types in particular are common but their basic properties are poorly understood) and science (detailed knowledge of primitive P or E-types, and metallic M-types). After C-type, M-type is a priority, but the nearest confirmed M-type metallic object is beyond the delta- $\mathrm{V}$ capability for a SIMONE rendezvous. Hence, a resonant orbit encounter strategy ${ }^{8}$ has been formulated by Telespazio for periodic brief flybys of the M-type asteroid Amun in the event that neither of the selected X-types are determined to be an M-type object. The C-type object 1996 FG3 is a high priority for science reasons, since it is a binary, i.e. two objects orbiting one another.

\section{Science Objectives}

The primary mission objectives of the SIMONE mission at each different NEO are to determine (in priority order):

- Bulk density: requiring both the mass and volume (size, shape) to be measured. For the particular spectral/physical class, it then allows predictions of the mass (and thus impact energy) to be made for other objects that are determined to be of the same class from ground observations. Bulk density can also be an indication of porosity;

- Gravity field: spherical/elliptical harmonics of the gravity field, together with a shape model, allow the derivation of large-scale internal density variations using a mass distribution model. These variations may have a bearing on the dynamical behaviour of a similar object on Earth approach, entry and impact, as well as providing extra evidence as to the internal structure for aiding mitigation strategy development;

- Surface topography/morphology: the highresolution surface information, in conjunction with compositional information, can be interpreted to give indications as to the object's internal structure. Surface features to examine include craters, grooves, fracture lines, regolith and boulders. From surface measurements, a detailed shape model will be constructed to improve mass and hence bulk density determination accuracy;

- Composition: provides spatial information to allow macroporosity to be estimated. Precise elemental/mineralogical composition can only be determined by a spacecraft encounter. Variations in composition across the surface will be correlated with topographic/morphological features, adding to the information available for assessment of the object's sub-surface properties/structure.

\section{Science Payload}

The baseline science payload instruments identified and selected to achieve these objectives are described in Table 3.

The total mass of the full baseline payload selection is only $13 \mathrm{~kg}$ (including margin). It has been found that all instruments can be accommodated on-board the SIMONE spacecraft design, all aligned along the same boresight (i.e. viewing from the same face) and within the available mass budget. Their power, data handling and communications requirements can also be fully satisfied. Further information on the science aspects of SIMONE is in preparation ${ }^{9}$. 
Table 3. Baseline payload selection for each SIMONE microsatellite

\begin{tabular}{|c|c|c|c|}
\hline Experiment & Measurement Objectives & Heritage & Performance \\
\hline $\begin{array}{l}\text { Multispectral } \\
\text { Imaging System } \\
\text { (MIS) }\end{array}$ & $\begin{array}{l}\text { Size, shape, surface topography / } \\
\text { morphology } \\
\text { Contributes to bulk density, } \\
\text { mineralogical composition, rotation } \\
\text { state and binarity }\end{array}$ & $\begin{array}{l}\text { SMART-1 mission } \\
(2003)\end{array}$ & $\begin{array}{l}5.3^{\circ} \times 5.3^{\circ} \text { field-of-view } \\
1024 \times 1024 \text { pixel CCD } \\
\text { 4-position filter wheel from } \\
\text { visible to near-IR } \\
\text { Resolution } 1 \mathrm{~m} \text { at } 11 \mathrm{~km}\end{array}$ \\
\hline $\begin{array}{l}\text { Radio Science } \\
\text { Investigation (RSI) }\end{array}$ & $\begin{array}{l}\text { Mass -> bulk density } \\
\text { Gravity field }\left(\mathrm{J}_{2}\right)\end{array}$ & $\begin{array}{l}\text { 2-way Doppler using X- } \\
\text { band comms system } \\
\text { Mars Express (2003), } \\
\text { Rosetta missions }\end{array}$ & $\begin{array}{l}\text { Range rate } \sim 0.03 \mathrm{~mm} \mathrm{~s}^{-1} \\
\text { over } 100 \mathrm{~s} \\
\text { Range } 1-10 \mathrm{~m}\end{array}$ \\
\hline $\begin{array}{l}\text { X-Ray Spectrometer } \\
\text { (XRS) }\end{array}$ & $\begin{array}{l}\text { Elemental composition of most rock } \\
\text { forming elements; potential for } \mathrm{C} \\
\text { detection }\end{array}$ & $\begin{array}{l}\text { SMART-1 mission } \\
(2003)\end{array}$ & $\begin{array}{l}2-10^{\circ} \text { field-of-view } \\
0.5-10 \mathrm{keV} \text { energies } \\
<150 \mathrm{eV} \text { resolution }\end{array}$ \\
\hline $\begin{array}{l}\text { Near-Infrared } \\
\text { Spectrometer (NIS) }\end{array}$ & $\begin{array}{l}\text { Mineralogical composition across } \\
\text { surface }\end{array}$ & $\begin{array}{l}\text { SMART-1 mission } \\
(2003)\end{array}$ & $\begin{array}{l}1.11 \mathrm{mrad} \text { field-of-view } \\
0.94-2.4 \mu \mathrm{m} \text { wavelengths } \\
6 \mathrm{~nm} \text { resolution }\end{array}$ \\
\hline $\begin{array}{l}\text { Laser Altimeter } \\
(\mathrm{ALT})\end{array}$ & $\begin{array}{l}\text { Size, shape, surface topography / } \\
\text { morphology } \\
\text { Contribution to mass, gravity field, bulk } \\
\text { density }\end{array}$ & $\begin{array}{l}\text { Clementine mission } \\
(1994) \\
1 \mathrm{~m} \text { resolution upgrade } \\
\text { needed }\end{array}$ & $\begin{array}{l}<0.5 \mathrm{mrad} \text { beam diverge } \\
0.057^{\circ} \text { field-of-view }\end{array}$ \\
\hline
\end{tabular}

\section{The Spacecraft}

\section{Spacecraft Design}

The SIMONE microsatellites are 3-axis stabilised platforms with integrated avionics, an on-board Xenon ion propulsion system and an X-band communication system with an integral high gain antenna for TT\&C data transfer at long ranges from Earth. Two lightweight high power solar array wings generate $1 \mathrm{~kW}$ (maximum), sufficient to drive all subsystems and payload.
The autonomous attitude control system comprises 4 reaction wheels and 6 small hollow cathode thrusters for momentum dumping. On-board attitude determination is performed by redundant sun sensors, gyros and star trackers. The spacecraft has been designed to survive a high radiation exposure (dose damage and solar array degradation), the launch vibration environment and the extremes of the thermal environment expected during all 5 rendezvous missions over a maximum mission lifetime of 5 years. A summary specification is given in Table 4.

\section{Table 4. Specification of the SIMONE microsatellite system design}

\begin{tabular}{|c|c|c|}
\hline Characteristic & Summary & Comments \\
\hline Launch mass & $120 \mathrm{~kg}$ & Bus body dimensions of $600 \times 600 \times 710 \mathrm{~mm}$ \\
\hline Propulsion & T5 carbon-gridded ion engine & $\begin{array}{l}\text { Specific impulse: } 4,500 \mathrm{~s} \\
\text { Nominal thrust: } 18 \mathrm{mN} \\
\text { Lifetime: }>30,000 \text { hours }\end{array}$ \\
\hline Propellant & Up to $27 \mathrm{~kg}$ of high purity xenon & Stored at 105 bar BoL \\
\hline Power generation & $\begin{array}{l}1 \mathrm{~kW}(\mathrm{BoL}, \mathrm{AM0} \text { and } 1 \mathrm{AU}) \\
278 \mathrm{~W}(\mathrm{EoL}, \mathrm{AM} 0 \text { and } 2 \mathrm{AU})\end{array}$ & $\begin{array}{l}\text { New hybrid array development using triple-junction } \\
\text { GaAs cells }\end{array}$ \\
\hline Power storage & 150Whr (BoL) & Li-ion cells \\
\hline Onboard computer & 1750a (16bit machine, 2MIPS) & Radiation-hard, dual-redundant, autonomous FDIR \\
\hline Data Storage & $\begin{array}{l}\text { 512Mbit 3D DRAM for payload data } \\
\text { 4Mbit for housekeeping storage }\end{array}$ & Radiation-hard, dual redundant \\
\hline Communications & X-band & $0.5 \mathrm{~m}$ HGA to 12 or $35 \mathrm{~m}$ ground antenna \\
\hline Uplink rate & Up to $300 \mathrm{kbps}$ & Selectable \\
\hline Downlink rate & 1.4kbps (minimum) & For a SIMONE-Earth distance of $2 \mathrm{AU}$ \\
\hline Attitude control & $\begin{array}{l}\text { Absolute pointing: } 0.01^{\circ} \\
\text { Relative pointing: } 10 \operatorname{arcsec} \text { in } 10 \mathrm{~s} \\
\text { Autonomous }\end{array}$ & $\begin{array}{l}\text { 3-axis using Momentum Wheels \& Hollow Cathode } \\
\text { Thrusters (HCTs). HCTs use the same propellant supply } \\
\text { as the main engine }\end{array}$ \\
\hline Attitude knowledge & Knowledge to better than $0.01^{\circ}$ & Sun and Star Sensors \\
\hline
\end{tabular}




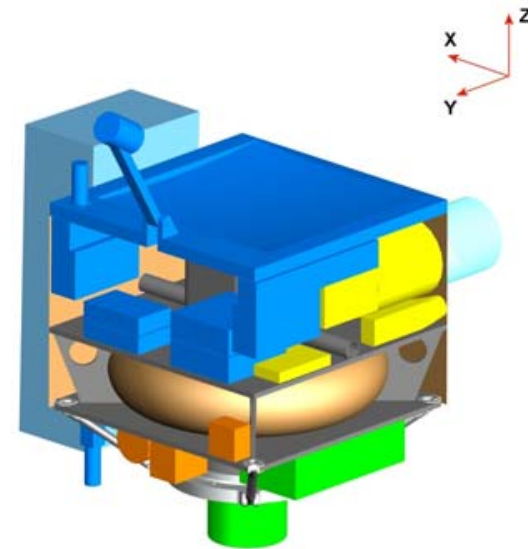

Overhead $Y /-X$ view

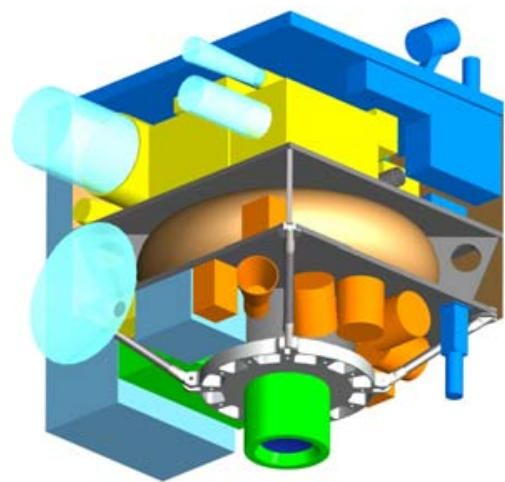

Underside $X /-Y$ view

Figure 3. SIMONE spacecraft configuration (exterior panels and solar array wing removed for clarity)

A 3D CAD model of the SIMONE spacecraft is presented in Figure 3. This modelling was essential in order to perform a detailed accommodation analysis. It was established that all selected subsystem and payload equipment could fit within the tight volume constraints of the Ariane 5 ASAP launch. This was also necessary to complete a bus structure design that is not only lightweight, but also strong/stiff enough to secure equipment and survive the launch environment. To this end, finite element modelling of the structure (composite thrust tube, Al honeycomb/CFRP skin decks \& panels, Al support struts and adaptor ring) was performed. All requirements were comfortably met within a total structure mass of $20 \mathrm{~kg}$.

Some innovative design was necessary to accommodate high volume equipment such as the pressurised Xenon fuel tank. Instead of using a conventional spherical tank, a toroidal tank fitted around the central thrust tube is used, which enables a minimum spacing between the upper $\&$ lower decks. The tank is an inner steel liner over-wrapped with composite material. Such tanks have already been developed by QinetiQ for terrestrial applications. To save further space, the High Gain Antanna forms the top panel of the bus and the feed is offset on a small deployable boom. The on-board computer and data handling system, and Xenon gas flow system are housed within the central thrust tube, along with the solar array drive mechanisms.

Thermal control is needed primarily for the Travelling Wave Tube Amplifiers (TWTAs) in the comms system located on the top deck with the payload, and the Xenon pressure tank. The ion thruster is thermally isolated from the bus and radiates heat to space. Heat needs to be dissipated when the TWTAs are operating. This is done by embedding heat pipes in the radiator panels on the solar wing sides of the bus, which are in contact with the TWTAs. Small heaters are used to keep the non-operating TWTAs and pressure tank sufficiently warm at large solar distances. A thermal analysis was conducted to confirm the capability of the design within low mass.

All analyses indicate that the high performance microsatellite bus design proposed is feasible and can be built using current technology developments. Crucially, the ion propulsion and solar power systems can be integrated successfully to give the high power, high manoeuvrability capabilities.

\section{Ion Propulsion System}

The spacecraft design is dominated by the demanding total delta-V capability required to achieve a rendezvous with a typical NEO. The high specific impulse of the QinetiQ T5 gridded ion engine $(4,500 \mathrm{~s})$, together with its relatively small size, makes it the ideal candidate for this mission, since a low propellant mass can be achieved and the engine can be accommodated within the spacecraft mass budget. The $10 \mathrm{~cm}$ diam. T5 engine can be seen in Figure 4.

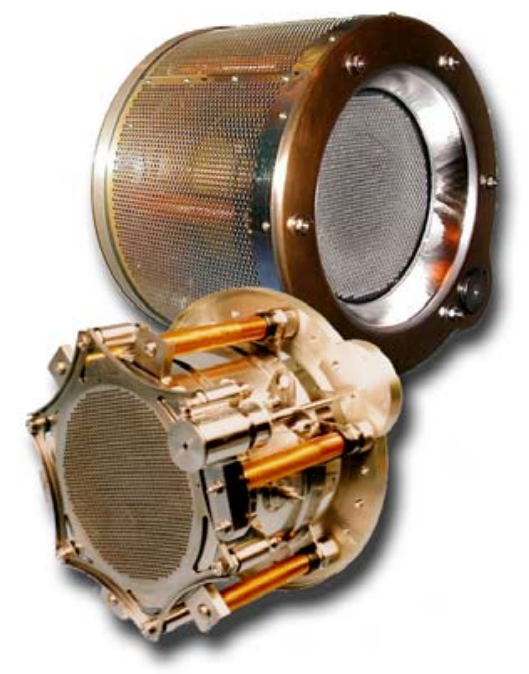

Figure 4. QinetiQ T5 ion thruster assembly 
The xenon propellant required for a delta- $\mathrm{V}$ capability of $10 \mathrm{~km} / \mathrm{s}$ is approximately $26 \mathrm{~kg}$ on a $120 \mathrm{~kg}$ spacecraft. With such a delta-V capability, nearly 60 NEOs become accessible for rendezvous by a SIMONE microsatellite. The flight times, fuel masses and engine on-times for each of the 5 SIMONE targets are given in Table 5. The T5 engine (with carbon acceleration grids) has a predicted total impulse capability of 3 million Ns and thrust range of $5-25 \mathrm{mN}$. This equates to, for example, over 30,000 hours of operation at a constant $18 \mathrm{mN}$ of thrust, sufficient for the selected rendezvous targets $(\sim 18,000$ hours). The thruster is baseline for the upcoming ESA GOCE mission, and is currently undergoing a comprehensive life testing/qualification programme.

Table 5. Ion propulsion performance per mission

\begin{tabular}{|l|c|c|c|}
\hline Target & $\begin{array}{c}\text { Flight } \\
\text { time (yrs) }\end{array}$ & $\begin{array}{c}\text { Xenon fuel } \\
\text { mass (kg) }\end{array}$ & $\begin{array}{c}\text { Engine } \\
\text { time (hrs) }\end{array}$ \\
\hline 1989 UQ & 2.67 & 25.0 & 17,030 \\
\hline 2001 CC21 & 2.67 & 23.3 & 15,873 \\
\hline 1996 FG3 & 3.55 & 22.2 & 15,124 \\
\hline Nereus & 2.95 & 20.9 & 14,238 \\
\hline 1999 YB & 3.06 & 21.0 & 14,306 \\
\hline
\end{tabular}

\section{Lightweight High Power Solar Array}

A solar array output of $\sim 550 \mathrm{~W}$ is required to power the $\mathrm{T} 5$ engine (for $18 \mathrm{mN}$ of thrust). Radiation degradation and the larger distances from the Sun during the encounter, increase the beginning of life power requirement to $1 \mathrm{~kW}$ (measured at the Earth). Clearly, a lightweight deployable array, which when stowed is highly compact, is therefore also critical to the design. In order to significantly reduce the mass and volume of the solar array to within the launch constraints, a new array technology is being developed at QinetiQ whereby 28\% efficient GaAs solar cells are attached to pre-tensioned membranes mounted within rigid tubular frames (see Figure 5).

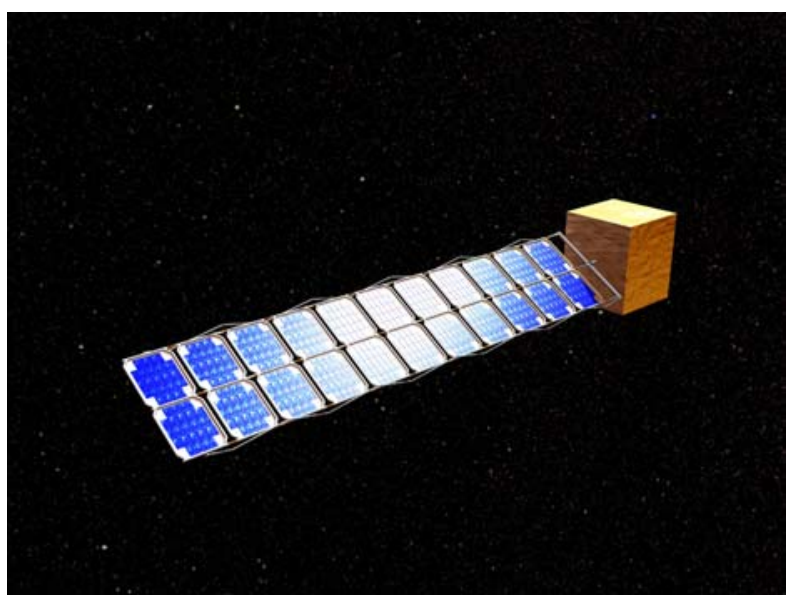

Figure 5. QinetiQ lightweight high power solar array
Thick coverglass is used to reduce performance degradation due to radiation exposure, especially during the first month of the mission when the spacecraft is still passing through Earth's trapped proton belt at perigee. Each of the two steerable array wings have 11 panels and are $3.3 \mathrm{~m} \times 0.7 \mathrm{~m}$ in area. When stowed, each wing occupies a volume of $0.3 \mathrm{~m}$ $\mathrm{x} 0.7 \mathrm{~m} \times 0.2 \mathrm{~m}$. Deployment is controlled and synchronised. The total mass of the two wings is only $16 \mathrm{~kg}$. Alternative solar arrays such as the stretched lens arrays being developed under NASA funding are also being considered for use in the power system.

\section{Mass Budget}

The mass budget of each SIMONE spacecraft is based upon identification of known COTS components and associated suppliers able to meet the specification, QinetiQ technology development programmes, and the application of margin where existing items require modifications. The propellant mass includes a $10 \%$ margin and fuel for ADCS. Overall, the mass budget presented in Table 6 contains $11 \mathrm{~kg}$ of margin and $6 \mathrm{~kg}$ of redundant equipment. This enables dual redundancy of critical components, including: the onboard data handling unit (processor and memory); communications system (low gain antennas, transmitters, receivers and TWTAs); and the attitude determination \& control system (gyros, star tracker heads and reaction wheels).

\begin{tabular}{|l|c|c|}
\hline Subsystem & Mass $(\mathrm{kg})$ & Mass Fraction (\%) \\
\hline ADCS & 6.9 & 5.8 \\
\hline Propulsion & 16.4 & 13.7 \\
\hline Power & 23.3 & 19.4 \\
\hline Avionics & 11.1 & 9.2 \\
\hline Mechanical & 19.4 & 16.2 \\
\hline Payload & 13.1 & 10.9 \\
\hline Dry mass total & 90.2 & 75.2 \\
\hline Propellant & 29.8 & 24.8 \\
\hline Wet mass total & 120 & 100 \\
\hline
\end{tabular}

Table 6. SIMONE spacecraft mass budget

\section{The Ground Segment}

All SIMONE spacecraft will be identical in design and will have the same operational requirements for Telemetry, Tracking and Command (TT\&C). Hence to lower recurring costs, a single mission control centre and a single ground station is foreseen to support the concurrent flight operations of all SIMONE spacecraft. Ground station costs are minimised by the use of a small 'near-Earth' ground station, transferring to leasing of link time on a commercial deep space network for deep space operations. In order to further reduce operations costs, the SIMONE spacecraft will have a degree of onboard autonomy to enable 'off-line' operations during non-critical periods of the missions and to minimise ground station usage. It is envisaged that a smaller 
(and lower cost) near-Earth ground station will be used during the LEOP, check-out, Parking orbit and Earth escape phases of the missions. The spacecraft will be handed over to a larger deep space ground station to facilitate the required TT\&C communications links with the spacecraft during the Interplanetary transfer, Rendezvous and Measurement phases of the missions. The ground segment architecture is illustrated in Figure 6.

The single mission control centre includes dedicated teams for the telemetry \& command data handling of each SIMONE spacecraft. The mission control centre will be responsible for distribution of downlinked payload data from all SIMONE spacecraft to the science data centre for later processing and on-line distribution to the science community using established science data centres. Mission planning and flight dynamics functions provide simultaneous operational support to all SIMONE spacecraft. All SIMONE spacecraft will utilise the same system architecture and software, including that for orbit determination from tracking data, orbit and attitude manoeuvre planning, event sequencing, spacecraft system simulation, command generation for uplink, and telemetry data processing and monitoring. Re-use of existing systems, such as the ESA SCOS 2000 mission control software, is foreseen in order further reduce development costs.

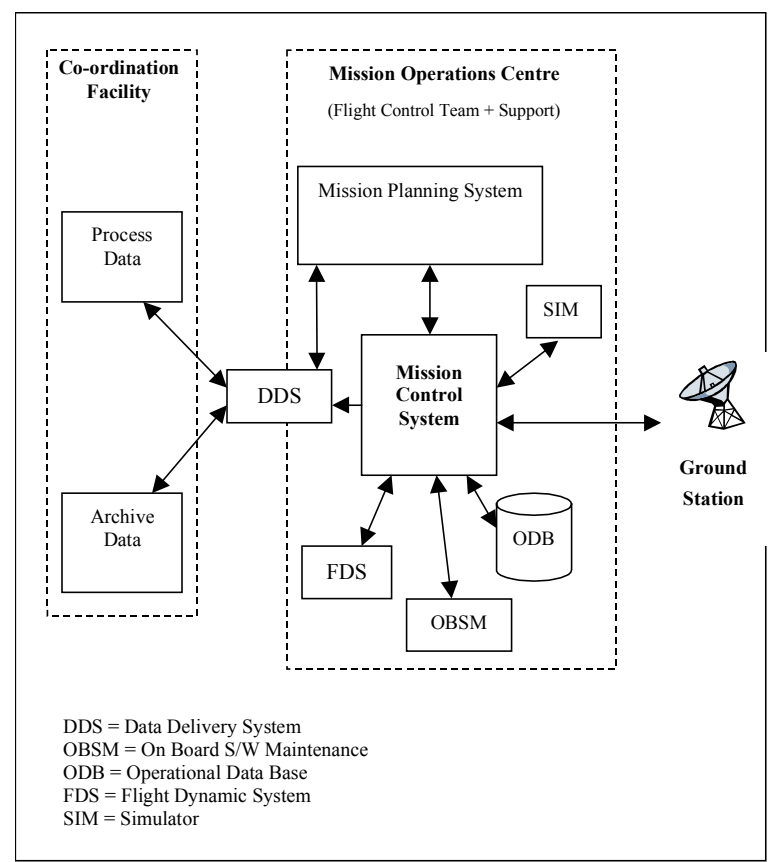

Figure 6. Ground segment architecture

The preferred baseline for spacecraft navigation is for a combination of radio and optical navigation. Radio navigation (using two-way Doppler tracking data at $\mathrm{X}$-band) achieves a high precision range rate and is also used by the Radio Science Investigation during the Measurement phase at the target NEO. Optical navigation (taking advantage of the Multispectral Imager payload instrument) is used for the NEO acquisition, approach and terminal guidance phase. This choice results from a compromise between the requirements of cost, complexity, onboard resource limitations and required accuracy. The image processing and orbit calculations associated with the navigation function are planned to be undertaken on the ground. Special software tools are required to perform the low-thrust interplanetary navigation, rendezvous and 'formation flying' manoeuvre calculations at the NEO target.

\section{Conclusions}

It is clear that to achieve an ambitious interplanetary mission, such as asteroid rendezvous, within $120 \mathrm{~kg}$ mass and the confines of a microsatellite is a challenging goal. However, such a high-performance microsatellite bus is now feasible due to the emergence of a variety of key technologies including:

- Highly compact, yet capable, scientific instruments, enabling the baseline payload to be achieved within $13 \mathrm{~kg}$.

- A solar array (2 wings) that stows into a volume of 84 litres, has a mass of only $16 \mathrm{~kg}$ but can generate $1 \mathrm{~kW}$ using the latest triple-junction GaAs cells.

- A small gridded ion engine that is now a mature technology. In its latest variant (with graphite acceleration grids), the engine can exceed the necessary lifetime and total impulse requirements for an interplanetary mission like SIMONE.

- Small Hollow Cathode Thrusters that efficiently perform attitude control wheel momentum dumping direct from the main Xenon tank, rather than needing a separate cold gas thruster system.

- High-density, high-efficiency electronics and RF equipment (processors, memories, amplifiers, travelling wave tubes, etc.) that allow a flexible, capable data handling and communications architecture within a few kilograms.

- High-stiffness fibres and matrices that allow the construction of very lightweight spacecraft structures and pressurised gas propellant tanks with minimum mass.

- Small sensors and actuators (star cameras, sun sensors, momentum wheels and gyros) that offer high performance attitude and orbit control, but from devices that are $<1 \mathrm{~kg}$ each in mass.

Furthermore, the scale of economics with such a mission is a fraction of that normally associated with a larger, conventional mission. Significant cost savings arise from a rapid development schedule, a piggyback launch and commercial deep space ground station usage. However, the science return is not significantly compromised. Thus, it can be concluded that the "interplanetary microsatellite" is now not 
only realisable in the short-term, but also a very costeffective tool in solar system exploration. This can be exploited to make deep space more accessible with a single spacecraft, or to perform distributed exploration tasks with a network of multiple spacecraft as in the case of the SIMONE mission.

\section{$\underline{\text { Outlook }}$}

With a significant delta-V capability of $10 \mathrm{~km} / \mathrm{s}$ provided by the T5 gridded ion propulsion system, near-Earth asteroids are not the only objects accessible to these high performance microsatellites. Mars Micro Missions are also being actively studied. Launched together onto a direct escape trajectory on a single low-cost Russian launcher, several such microsatellites can reach a low Mars orbit where they can form an orbiting constellation suitable for global atmospheric monitoring, communications data relay with surface assets and navigation services for other Mars missions. Slightly larger ion-propelled minisatellites are also being considered to carry larger payloads. Alternatively, the high performance, lowcost microsatellites may have high maneouvre applications in Earth orbit, such as GTO-to-GEO transfer or plane changes in LEO for rendezvous and close inspection.

\section{$\underline{\text { Acknowledgements }}$}

The authors would like to thank the other members the SIMONE mission study team for their contributions: Prof. Franco Bernelli, Mauro Massari of Politecnico di Milano; Dr. Ettore Perozzi of Telespazio; Martin Townend of SciSys; Martin Pätzold of University of Cologne; Glyn Dando, Mark Butcher, Matt Cosby, Steve Kynaston, Mike Price, Pete Jameson, Dave Mundy, Neil Wallace, Alan Freeman, Harj Jolly, Neil Redit, Chris Yates and Simon Clucas of QinetiQ.

This work was funded by the European Space Agency as part of preparatory activities for NEO space missions. The project was supervised by Andrés Galvez of the Advanced Concepts Team at ESTEC, Holland, with support from the Spaceguard Central Node at ESRIN, Italy.

\section{$\underline{\text { References }}$}

1. Whitcomb, G.P., "The ESA approach to low-cost planetary missions", Acta Astronautica 52 (2003)79-86.

2. Brophy, J., "Advanced ion propulsion systems for affordable deep-space missions", Acta Astronautica 52 (2003)309-316.

3. Wells, N., "SIMONE: Smallsat Missions to Objects Near Earth -an NEO Space Mission Preparation study", Final Report to ESA contract 16254-02-F-IZ, January 2003.
4. Massari, M., Bernelli-Zazzera, F., Vasile, M., "Trajectory Optimization for a Mission to NEOs Using Low-thrust Propulsion and Gravity Assist", paper AAS-03-120, 13 ${ }^{\text {th }}$ AAS/AIAA Space Flight Mechanics meeting, Puerto Rico, 9-13 February 2003.

5. Atkinson, H. et al: "Report of the Task Force on Potentially Hazardous near Earth Objects", DTI/Pub4990/5k/9/00/NP.URN00/1041, UK DTI report, September 2000.

6. R.P. Binzel, E. Perozzi, A.S. Rivkin, A. Rossi, A.W. Harris, S.J. Bus, G.B. Valsecchi: "Dynamical and Compositional Assessment of Near-Earth Object Mission Targets”, Planetary $\&$ Space Science, in preparation.

7. Christou, A., "The statistics of ight opportunities to accessible near-Earth asteroids", Planetary and Space Science 51 (2003) $221-231$.

8. Perozzi, E., A. Rossi, G.B. Valsecchi, Basic Targeting Strategies for Rendezvous and Flyby Missions to the Near Earth Asteroids, Planetary and Space Science, 49 (2001) 3-22.

9. Green, S.F., Ball, A.J., Zarnecki, J.C., Wells, N.S., Walker, R.J., Bernelli-Zazzera, F., Massari, M., Perozzi, E., Pätzold, M. and Townend, M., "SIMONE: A Fleet of NearEarth Object Rendezvous Microsatellites", Planetary \& Space Science, in preparation.

C QinetiQ Ltd. 2003. 